\title{
Differential Effect of Extracellular Acidic Environment on IL-1 $\beta$ Released from Human and Mouse Phagocytes
}

\author{
Petra Sušjan ${ }^{1}$, Mojca Benčina ${ }^{1,2}$ and Iva Hafner-Bratkovič ${ }^{1,2, *(D)}$ \\ 1 Department of Synthetic Biology and Immunology, National Institute of Chemistry, Hajdrihova 19, \\ 1000 Ljubljana, Slovenia; petra.susjan@ki.si (P.S.); mojca.bencina@ki.si (M.B.) \\ 2 EN-FIST Centre of Excellence, Trg Osvobodilne fronte 13, 1000 Ljubljana, Slovenia \\ * Correspondence: iva.hafner@ki.si; Tel.: +386-1-4760-393
}

Received: 29 June 2020; Accepted: 28 September 2020; Published: 30 September 2020

check for updates

\begin{abstract}
Areas of locally decreased $\mathrm{pH}$ are characteristic for many chronic inflammatory diseases such as atherosclerosis and rheumatoid arthritis, acute pathologies such as ischemia reperfusion, and tumor microenvironment. The data on the effects of extracellular acidic $\mathrm{pH}$ on inflammation are conflicting with respect to interleukin 1 beta (IL-1 $\beta$ ) as one of the most potent proinflammatory cytokines. In this study, we used various mouse- and human-derived cells in order to identify potential species-specific differences in IL-1 $\beta$ secretion pattern in response to extracellular acidification. We found that a short incubation in mild acidic medium caused significant IL-1 $\beta$ release from human macrophages, however, the same effect was not observed in mouse macrophages. Rather, a marked IL- $1 \beta$ suppression was observed when mouse cells were stimulated with a combination of various inflammasome instigators and low $\mathrm{pH}$. Upon activation of cells under acidic conditions, the cytosolic $\mathrm{pH}$ was reduced while metabolic activity and the expression of the main inflammasome proteins were not affected by low $\mathrm{pH}$. We show that IL-1 $\beta$ secretion in mouse macrophages is reversible upon restoration of physiological $\mathrm{pH}$. $\mathrm{pH}$ sensitivity of NLRP3, NLRC4 and AIM2 inflammasomes appeared to be conferred by the processes upstream of the apoptosis-associated speck-like protein containing a CARD (ASC) oligomerization and most likely contributed by the cell background rather than species-specific amino acid sequences of the sensor proteins.
\end{abstract}

Keywords: acidosis; IL-1 $\beta$; inflammasome; species-specific; NLRP3

\section{Introduction}

Local acidosis is the hallmark of many chronic inflammatory diseases. Dense infiltration of neutrophils and macrophages to the affected sites causes acidosis through massive amount of protons released through neutrophil respiratory burst and through an increased consumption of oxygen, which consequently results in hypoxia, a switch toward glycolytic metabolism, and accumulation of lactic acid [1]. A drop in local pH (pH 7-6) can be observed in pathologies such as ischemia [2] and atherosclerotic plaques [3]. Similarly, in patients with rheumatoid arthritis, the $\mathrm{pH}$ of synovial fluid is significantly lower than in healthy individuals [4]. Low extracellular $\mathrm{pH}$ and hypoxia are also characteristic features of the tumor microenvironment where accumulation of protons and development of hypoxic regions is enabled through high metabolic demand, hydration of $\mathrm{CO}_{2}$, and disorganized tumor vascular architecture [5]. The existing literature appears to be in dispute in terms of how $\mathrm{pH}$ affects the local inflammatory responses, as studies report both synergistic and antagonistic effects of acidosis on various inflammatory mediators. On one hand, slight acidosis was shown to enhance communication between complement pathways important for antimicrobial response 
to hospital-acquired infection with Pseudomonas aeruginosa [6]. Similarly, NO formation by murine macrophages was shown to be upregulated in slightly acidic conditions, mainly on a post-transcriptional level [7]. On the other hand, tumor necrosis factor (TNF) and interleukin 6 (IL-6) release from various murine cell lines was reported to be inhibited under acidic conditions [8]. Dispute may be attributed to the species-specific differences in innate immunity signaling. Extensive divergence between humans and mice was, for example, identified in liposaccharide (LPS)-regulated gene expression and attributed to its large dynamic range [9].

One of the main proinflammatory cytokines is IL-1 $\beta$. Few studies have directly addressed its secretion pattern in human or mouse macrophages under acidic conditions, despite clear indications that a perturbation of ion homeostasis has a crucial role in the regulation of inflammasomes, particularly of NLRP3 (NLR family protein containing a pyrin domain 3) inflammasome [10-12] as one of the main molecular drivers of IL-1 $\beta$ secretion. Inflammasomes are multi-protein cytosolic platforms composed of sensor proteins, adaptor proteins ASC (apoptosis-associated speck-like proteins containing a caspase activation and recruitment domain, CARD) and precursor proteins procaspase-1, which rapidly assemble in response to diverse microbial molecules (PAMP) and damage-associated molecules (DAMP), often found at the site of chronic inflammation [13,14]. Autocatalytically activated caspase-1 in turn activates pyroptosis through gasdermin D cleavage and inflammatory cytokine IL-1 $\beta$ and IL-18 secretion from macrophages, thus eliciting a potent inflammatory response that recruits other immune cells to the affected site [15]. Extracellular acidosis was suggested to act as a novel NLRP3 inflammasome trigger upon observing a caspase- 1 and potassium efflux-dependent IL- $1 \beta$ release from human monocytes and macrophages under mildly acidic conditions [16,17] as well as its inhibition under alkaline conditions [17]. In mice with colitis, on the other hand, IL-1 $\beta$ release was dampened when exposed to hypoxic conditions that often lead to acidosis. Some reports also suggest that acidosis differently modulates expression of IL-1 $\beta$ in monocytes and macrophages $[16,18]$.

In this study, we aimed to systematically investigate the effect of the pathologically relevant $\mathrm{pH}$ decrease on the IL-1 $\beta$ secretion from various human- and mouse-derived monocytes/macrophages. We show that while mild decrease in $\mathrm{pH}$ alone caused substantial IL-1 $\beta$ secretion from human macrophages, mouse macrophages did not exhibit any IL-1 $\beta$ release. Rather, we observed a marked IL-1 $\beta$ secretion suppression when mouse macrophages were stimulated with various inflammasome instigators under acidic conditions. The inhibition was not a consequence of poor cell viability, protein degradation, or stunted protein expression/translation under acidic conditions. We show that $\mathrm{pH}$ sensitivity of IL-1 $\beta$ secretion in mouse macrophages occurs upstream of ASC speck formation, is reversible, and depends on the cell origin species.

\section{Results}

\subsection{Low Extracellular pH Stimulated IL-1 $\beta$ Maturation in Primed Human Cells But Not in Murine Macrophages}

We first investigated the secretion pattern of IL-1 $\beta$ in human and mouse cell lines under various extracellular $\mathrm{pH}$ conditions. We started with human-derived BLaER1 B cells and transdifferentiated them into monocytes according to the published protocol [19]. BLaER1 monocytes were then primed with LPS and subsequently incubated in buffers with various physiologically and pathologically relevant $\mathrm{pH}(7.45,6.5,6$, and 8$)$. In accordance with the previous publication [17], cells responded to a decrease in $\mathrm{pH}$ from 6.5 to 6 , with secretion of IL-1 $\beta$ already within $1 \mathrm{~h}$ of incubation (Figure $1 \mathrm{a}, \mathrm{b}$ ). As acidosis alone had at this time-point not yet stimulated maximal IL- $1 \beta$ secretion, further IL- $1 \beta$ increase was observed with the addition of potent triggers ATP and nigericin, regardless of $\mathrm{pH}$. In the case of less potent particulate activators, acidosis triggered little to no additional IL-1 $\beta$ release (Figure 1b). Increase in IL-1 $\beta$ stimulation can only be observed in combination of particulate triggers with basic and neutral $\mathrm{pH}$, the conditions that on their own do not stimulate substantial secretion of IL-1 $\beta$ (Figure 1b). 


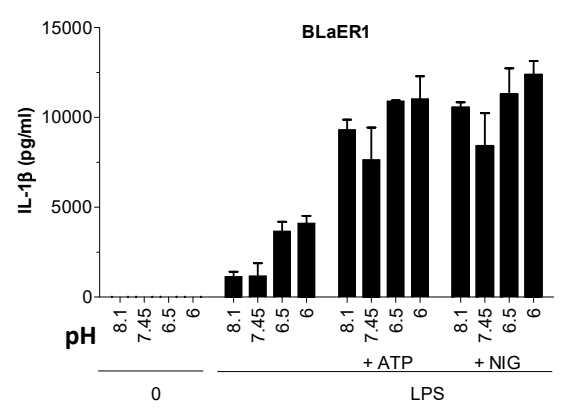

b

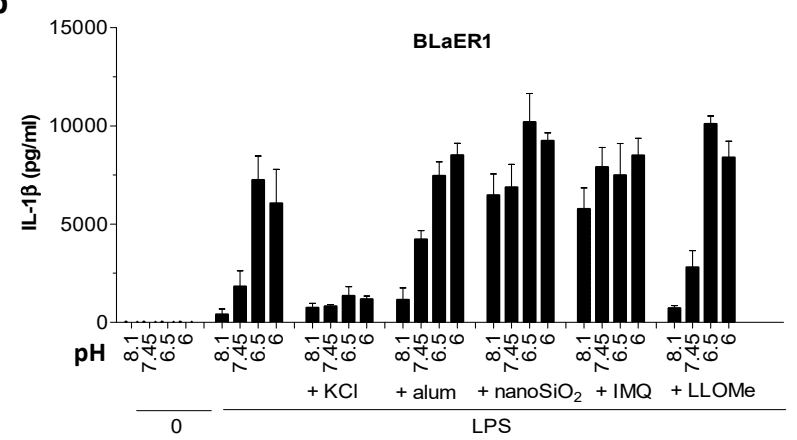

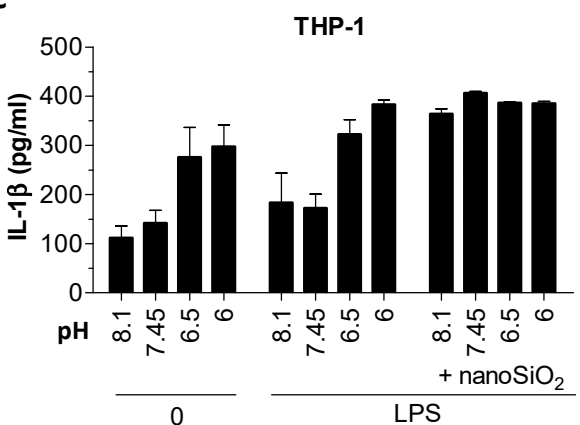

d

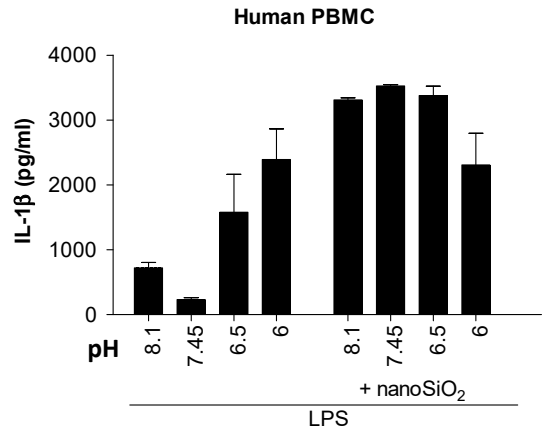

Figure 1. The effect of extracellular $\mathrm{pH}$ on interleukin 1 beta (IL-1 $\beta$ ) release from human monocytes and macrophages. (a) IL-1 $\beta$ levels in supernatants after the differentiated BLaER1 monocytes were primed with $100 \mathrm{ng} / \mathrm{mL}$ lipopolysaccharide (LPS) for $6 \mathrm{~h}$ and then treated for $1 \mathrm{~h}$ with stimulation buffers of various $\mathrm{pH}$ values alone or containing $5 \mathrm{mM}$ ATP or $10 \mu \mathrm{M}$ nigericin. (b) IL-1 $\beta$ levels after BLaER1 were primed as in (a) and treated for $3 \mathrm{~h}$ with buffers with various $\mathrm{pH}$ values alone or containing 134 $\mathrm{mM} \mathrm{KCl}, 400 \mu \mathrm{g} / \mathrm{mL}$ aluminum salts, $180 \mu \mathrm{g} / \mathrm{mL}$ nanoparticles of silica $\left(\right.$ nanoSiO $\left.{ }_{2}\right), 20 \mu \mathrm{M}$ imiquimod or $1 \mathrm{mM}$ L-leucyl-L-leucine methyl ester (LLoMe). (c,d) IL-1 $\beta$ levels by ELISA assay in supernatants after THP-1, differentiated with $100 \mathrm{ng} / \mathrm{mL}$ phorbol 12-myristate 13-acetate (PMA) or peripheral blood mononuclear cells (PBMCs) were primed with $100 \mathrm{ng} / \mathrm{mL}$ LPS for $6 \mathrm{~h}$ and exposed for $3 \mathrm{~h}$ to buffers with various $\mathrm{pH}$ values alone or containing $180 \mu \mathrm{g} / \mathrm{mL}$ nanoSiO ${ }_{2}$.

The same pattern of acidic pH-stimulated IL- $1 \beta$ release was observed in other tested cells of human origin, THP-1 cells, differentiated with phorbol 12-myristate 13-acetate (PMA) (Figure 1c) and peripheral blood mononuclear cells (PBMCs) (Figure 1d). Acidic medium was reported to trigger NLRP3 inflammasome [17]. Indeed, the addition of $\mathrm{KCl}$, which counteracts the common NLRP3 inflammasome-activating process $\mathrm{K}^{+}$efflux [10], inhibited IL-1 $\beta$ release in response to acidic conditions (Figure 1b).

In contrast, when the same experiments were repeated on murine immortalized bone marrow-derived macrophages (iBMDMs), none of the $\mathrm{pH}$ conditions alone instigated any IL-1 $\beta$ maturation or pyroptosis within 1 hour (Figure $2 \mathrm{a}, \mathrm{b}$ ) or even after an extended period of incubation (Figure 3a). Cells appeared to be fully metabolically active after $1 \mathrm{~h}$ (Figure 2c) or $3 \mathrm{~h}$ (Supplementary Figure S1a), suggesting that low $\mathrm{pH}$ did not affect cell viability (Figure $2 \mathrm{c}$ ). The lack of IL-1 $\beta$ release in response to extracellular acidification was observed also in primary mouse bone marrow-derived macrophages (BMDM) (Figure 2d) and immortalized murine microglial cells (Figure 2e). This suggests that species-specific differences may exist between murine and human cells in terms of their IL-1 $\beta$ inflammatory response to an acidic environment. 


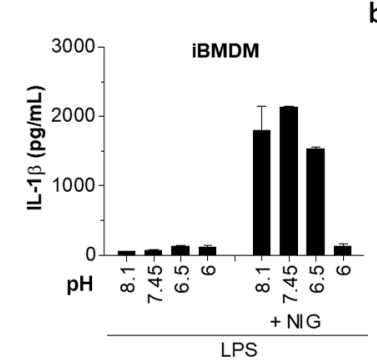

d

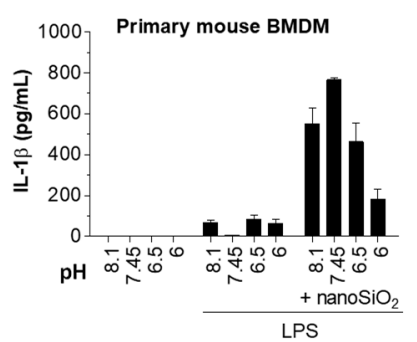

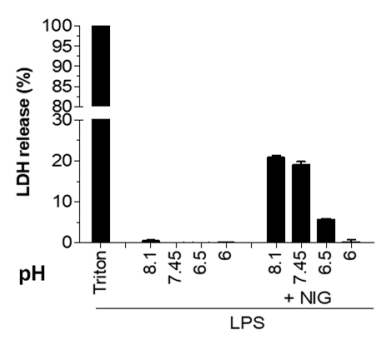

e

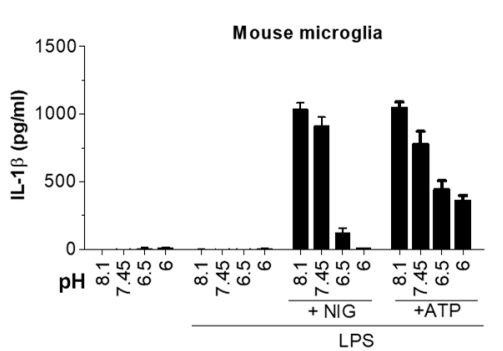

c
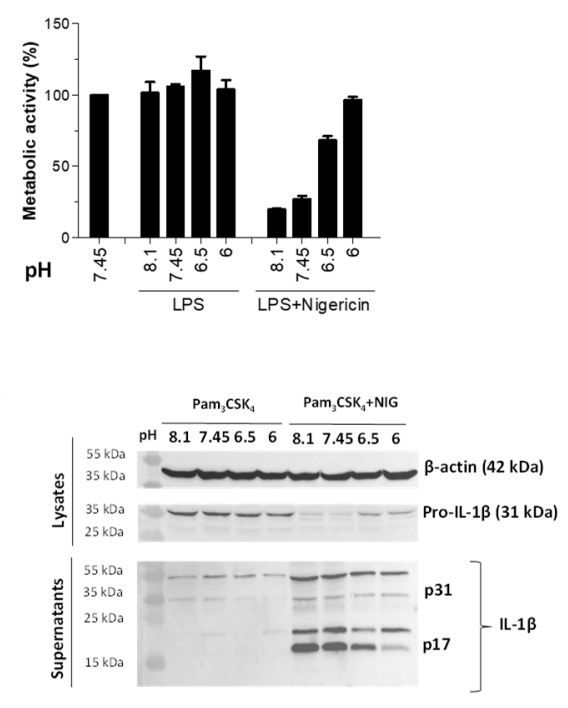

Figure 2. Decreased IL-1 $\beta$ maturation by acidosis in murine phagocytes. (a,b) IL- $1 \beta$ levels by ELISA assay (a) and lactate dehydrogenase (LDH) activity (b) in supernatants after immortalized bone marrow-derived macrophages (iBMDMs) were primed with $100 \mathrm{ng} / \mathrm{mL}$ LPS for $6 \mathrm{~h}$ and exposed to 10 $\mu \mathrm{M}$ nigericin in buffers with various $\mathrm{pH}$ values for $1 \mathrm{~h}$. (c) Metabolic activity of cells from experiment in (a) was followed by XTT assay. (d,e) IL-1 $\beta$ levels by ELISA assay in supernatants of primary mouse bone marrow-derived macrophages (BMDMs) (d) and mouse microglia cells (e) after priming as in $(\mathbf{a}, \mathbf{b})$ and $3 \mathrm{~h}$ stimulation with $180 \mu \mathrm{g} / \mathrm{mL}$ nanoSiO ${ }_{2}$ or buffers alone (d), or $1 \mathrm{~h}$ stimulation with 10 $\mu \mathrm{M}$ nigericin, $5 \mathrm{mM}$ ATP, or buffers alone (e). (f) Detection of IL- $1 \beta$ in supernatants and pro-IL- $1 \beta$ in lysates with Western blot after iBMDMs were treated overnight with $200 \mu \mathrm{g} / \mathrm{mL} \mathrm{Pam}_{3} \mathrm{CSK}_{4}$ and $1 \mathrm{~h}$ with $10 \mu \mathrm{M}$ nigericin or buffers alone.

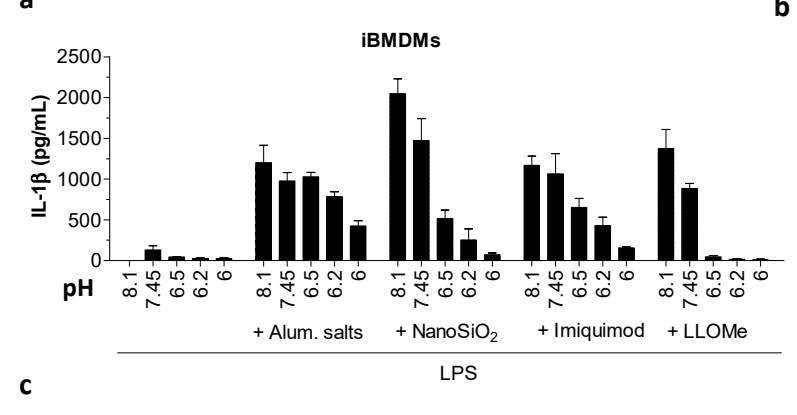

c

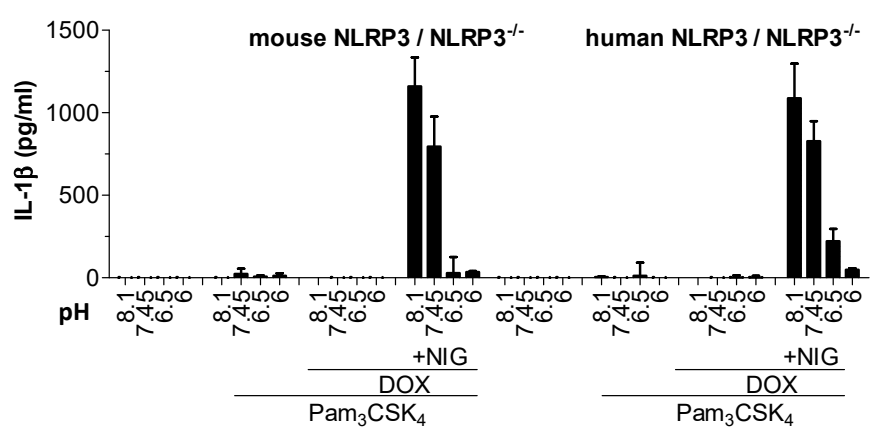

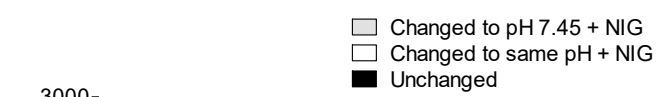

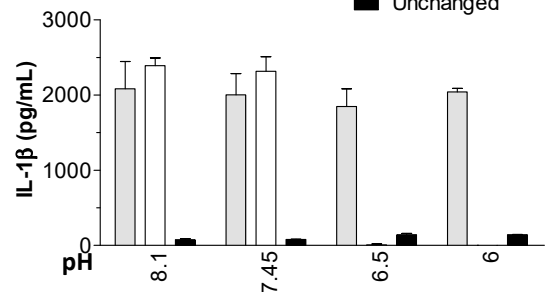

d

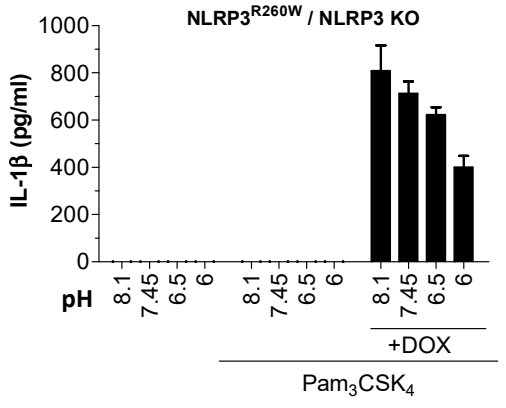

Figure 3. Acidic $p H$ decreased IL- $1 \beta$ secretion due to NLRP3 inflammasome canonical and constitutive activation. (a) IL-1 $\beta$ levels by ELISA after iBMDMs were primed with $100 \mathrm{ng} / \mathrm{mL}$ LPS for $6 \mathrm{~h}$ and treated $3 \mathrm{~h}$ with buffers with various $\mathrm{pH}$ values alone or containing $400 \mu \mathrm{g} / \mathrm{mL}$ aluminum salts, $180 \mu \mathrm{g} / \mathrm{mL} \mathrm{nanoSiO}_{2}$, 
$20 \mu \mathrm{M}$ imiquimod, or $1 \mathrm{mM}$ LLoMe. (b) IL-1 $\beta$ levels by ELISA assay in supernatants after iBMDMs were primed as in (a) and then incubated for $1 \mathrm{~h}$ in buffers with various $\mathrm{pH}$ values. Cells were then for another hour in either the same $\mathrm{pH}$ condition (unchanged), switched to a buffer with the same $\mathrm{pH}$ condition containing nigericin, or buffer with $\mathrm{pH} 7.45$ containing $10 \mu \mathrm{M}$ nigericin. (c,d) IL- $1 \beta$ levels by ELISA released from iBMDMs expressing reconstituted mouse or human NLRP3 (c) or NLRP3 ${ }^{\text {R260D }}$ mutant (d) after overnight priming with $200 \mathrm{ng} / \mathrm{mL} \mathrm{Pam}_{3} \mathrm{CSK}_{4}$ and $0.5 \mu \mathrm{g} / \mathrm{mL}$ doxycycline, followed by $1 \mathrm{~h}$ incubation in buffers with various $\mathrm{pH}$ values alone (c,d) or containing $10 \mu \mathrm{M}$ nigericin (c).

To determine whether the cytosolic $\mathrm{pH}$ of the murine macrophages is changed under acidic conditions, we transduced mouse iBMDMs with a $\mathrm{pH}$-sensitive green fluorescent protein (GFP) variant pHluorin. As this fluorescent protein has two excitation maxima depending on its protonation status (405 nm-deprotonated form, $488 \mathrm{~nm}$ - protonated form) [20,21], we were able to use the ratiometric cytometry method to measure the fluorescence in response to various $\mathrm{pH}$ conditions. When incubating the cells in acidic conditions alone, we observed a shift in the peak representing the fluorescence ratio between protonated and deprotonated forms of pHluorin towards the right, thus indicating a decrease in cytosolic pH (Supplementary Figure S1b). The ratio was shifted even further to the right when cells were treated with combined low $\mathrm{pH}$ conditions and various NLRP3 triggers, with the exception of the ionophore nigericin, which, as expected, equilibrated the extra- and intracellular $\mathrm{pH}$ through the pores (Supplementary Figure S1b). These results suggest the NLRP3 activators under acidic conditions further acidify the cell content of murine macrophages. The ability of murine macrophages to acidify the cytosol in response to acidic extracellular $\mathrm{pH}$ suggests that it is not the difference in response to $\mathrm{pH}$ that drives different effects on IL- $1 \beta$ secretion.

\subsection{Under Acidic Conditions, Murine Macrophages Suppressed IL-1ß Activation in Response to Various NLRP3 Inflammasome Triggers}

The inability of murine macrophages to secrete IL- $1 \beta$ in response to acidic $\mathrm{pH}$ prompted us to assess the effects of NLRP 3 inflammasome triggers on the IL-1 $\beta$ activation under acidic conditions. Not only did murine iBMDM in the presence of low $\mathrm{pH}$ yield no IL- $1 \beta$, its secretion and pyroptosis in response to nigericin were also markedly suppressed when stimulation was performed in the acidic buffer (Figure 2a,b). Furthermore, an increase in cell viability as judged from XTT assay was observed when nigericin treatment was performed in acidic $\mathrm{pH}$, which correlated to a decrease in pyroptosis (Figure $2 b, c)$. The same trend in IL-1 $\beta$ release suppression was observed with other murine phagocytes, primary mouse bone marrow-derived macrophages (BMDMs), and immortalized microglial cells (Figure 2d,e). The IL-1 $\beta$ maturation inhibition was further followed by Western blot (Figure 2f). While the amount of expressed cytokine precursor pro-IL-1 $\beta$ after incubation in acidic conditions alone was intact, thus excluding the effects on the precursor expression, we found a decreased amount of mature form of IL-1 $\beta$ (p17) in the cell supernatant as a result of nigericin treatment in acidic conditions. While very prominent with nigericin, this acidosis-related inhibitory effect was also observed with a wide array of other, chemically diverse NLRP3 instigators (Figure 3a) and was thus unlikely a consequence of potential trigger inactivation under acidic conditions.

\subsection{IL-1ß Activation in Response to Nigericin Was Rescued upon the Restoration of Physiological pH, Suggesting a Transient Effect That Does Not Depend on Irreversible Protein Modifications}

The activation mechanism of many inflammasomes, particularly NLRP3, still remains elusive, and thus some key proinflammatory signaling mediators could be inactivated under acidic conditions. We therefore tested whether IL- $1 \beta$ activation can be rescued upon restoration of physiological $\mathrm{pH}$. We first incubated iBMDMs with various $\mathrm{pH}$ buffers for $1 \mathrm{~h}$. In the next hour, we replaced the buffers either with physiological $\mathrm{pH}$ buffer containing nigericin or with the same $\mathrm{pH}$ buffer containing nigericin. In negative control, we kept cells in various $\mathrm{pH}$ buffers for the duration of the experiment. As expected, the cells secreted significantly less IL-1 $\beta$ when activated with nigericin in the presence of low $\mathrm{pH}$ (Figure $3 \mathrm{~b}$ ). However, when stimulated with nigericin after low $\mathrm{pH}$ buffer was replaced with 
physiological $\mathrm{pH}$ buffer, cells preincubated in acidic $\mathrm{pH}$ and stimulated with nigericin in physiological $\mathrm{pH}$ secreted a comparable amount of IL- $1 \beta$ to the cells without previous exposure to low $\mathrm{pH}$ (Figure $3 \mathrm{~b}$ ). As the expression of the degraded signaling mediators upon restoration of the physiological $\mathrm{pH}$ could theoretically be renewed through residual LPS priming or IL-1 $\beta$ positive feedback loop, we repeated the reversibility experiment using a stable cell line, where NLRP3 expression was dependent only on doxycycline induction. A complete restoration of IL-1 $\beta$ secretion upon restoration of physiological $\mathrm{pH}$ was observed (Supplementary Figure S2a), further indicating that irreversible degradation due to acidic conditions is likely not the cause of decreased inflammasome activation.

Intracellular acidification has been linked to the initiation of the apoptosis that is tightly associated with the proteasomal degradation of proteins [22]. Acidic conditions did not induce cell death in murine macrophages (Figure $2 \mathrm{c}$ and Supplementary Figure S1a). To fully eliminate the involvement of proteasomal degradation of proteins during acidic conditions, we treated iBMDMs with proteasome inhibitors before adding inflammasome triggers in the presence of low $\mathrm{pH}$ buffer. Proteasome inhibitors did not restore IL-1 $\beta$ release under acidic conditions (Supplementary Figure S2b), confirming that proteasomal degradation is not the reason behind the decreased inflammasome activation. Since the first activation signal (priming) of the inflammasome activation was performed under physiological $\mathrm{pH}$ conditions, it seems unlikely that protein translation could be affected by the $\mathrm{pH}$ change. While stimulation of cells with cycloheximide under physiological conditions resulted in a slight inhibitory effect on NLRP3 activation at physiological pH (Supplementary Figure S2c), the inhibition was not so profound to solely account for robust IL- $1 \beta$ inhibition observed with stimulation under acidic conditions.

Inhibition of IL-1 $\beta$ in response to acidic conditions could potentially affect the opening or oligomerisation of sensor proteins through direct protonation of amino acid residues, particularly histidines, under acidic conditions. We reasoned that if the differential IL- $1 \beta$ activation pattern is specific to the amino acid sequence of NLRP3, the human variant of NLRP3 expressed on the mouse cell background will retain its IL-1 $\beta$ stimulatory phenotype in response to acidic conditions. However, when human NLRP3 was introduced into NLRP3-deficient mouse macrophages, it did not support IL-1 $\beta$ maturation upon acidosis, which suppressed IL-1 $\beta$ secretion in response to inflammasome instigators (Figure $3 \mathrm{c}$ ). Further, we show that a previously identified shortest active truncation mutant lacking the LRR domain [23], mouse NLRP3 ${ }^{(1-686)}$, and human NLRP3 ${ }^{(1-688)}$ exhibited the same IL-1 $\beta$ inhibition pattern under acidic conditions as full length NLRP3 (Supplementary Figure S2d). Mutations in the gene encoding NLRP3 cause cryopyrin-associated periodic syndromes (CAPS). We show that acidic $\mathrm{pH}$ decreased constitutive cryopyrin-associated periodic syndromes mutation-associated IL-1 $\beta$ release, even when added after the inflammasome was already partially active (Figure 3d). Altogether, these data suggest that the differential $\mathrm{pH}$ sensitivity of IL-1 $\beta$ activation in response to acidic conditions is regulated by the cellular background, rather than being conferred by the sensor protein amino acid sequence.

\subsection{Acidosis Inhibited IL-1ß Release Due to NLRC4 and AIM2 Inflammasome Activation in Mouse Macrophages}

In addition to the NLRP3, a palette of other cytosolic sensor proteins can initiate the assembly of inflammasomes and trigger IL- $1 \beta$ release. Among inflammasome sensors, NLRP3 is regarded as the sensor of cellular homeostasis, and thus the most likely component to be affected by acidic $\mathrm{pH}$. Surprisingly, when cells were treated with Saty flagellin and poly(dA:dT), instigators of NLR family CARD domain-containing 4 (NLRC4) and absent in melanoma 2 (AIM2) inflammasomes, respectively, we observed similar acidosis-mediated IL-1 $\beta$ release inhibition (Figure $4 a, b)$, suggesting that acidosis does not selectively affect NLRP3 inflammatory responses in murine cells. Some studies suggest that within the inflammasome complex, sensor proteins might coexist in heterocomplexes [24]. The apparent pH-dependent IL-1 $\beta$ inhibition in response to NLRC4 and AIM2 inflammasome activators could thus be caused by the inhibition of NLRP3 within the heterocomplex. To investigate this possibility, we treated $\mathrm{NLRP}^{-/-}$iBMDMs with NLRC4 and AIM2 triggers under various $\mathrm{pH}$ conditions but were 
in both cases still able to detect a significant acidosis-dependent decrease in IL-1 $\beta$ secretion (Figure $4 c, d$ ). This suggests that rather than being a NLRP3-specific occurrence, $\mathrm{pH}$-sensitive processing of IL-1 $\beta$ is likely a more collective feature of the inflammasome signaling. Low IL-1 $\beta$ response was also not the consequence of ELISA detection malfunction under acidic conditions, as the IL- $1 \beta$ standard was normally detected even when combined with low $\mathrm{pH}$ stimulation buffer (Supplementary Figure S3); moreover, the mouse IL-1 $\beta$ ELISA we used was not specific for the mature version of IL-1 $\beta$, and thus pro-IL-1 $\beta$ and other species (e.g., p20) could also be detected. In addition, we verified our findings by replacing HEPES with bisTRIS propane buffer to ensure that the observed IL- $1 \beta$ and pyroptosis inhibition was not limited to the type of buffer used (data not shown).

a

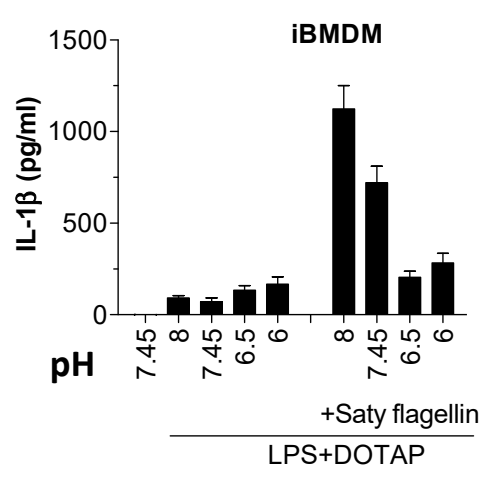

c

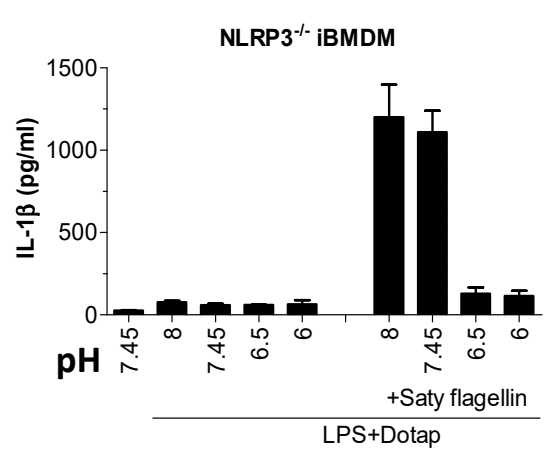

b

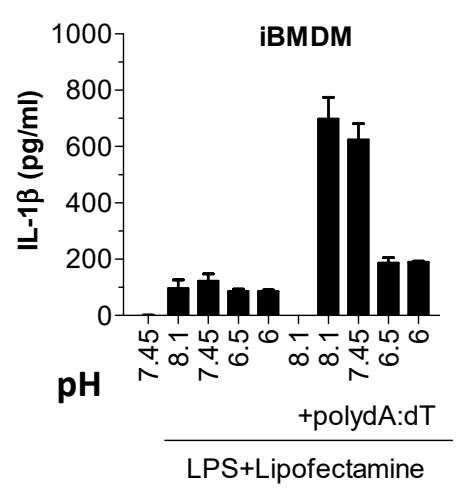

d

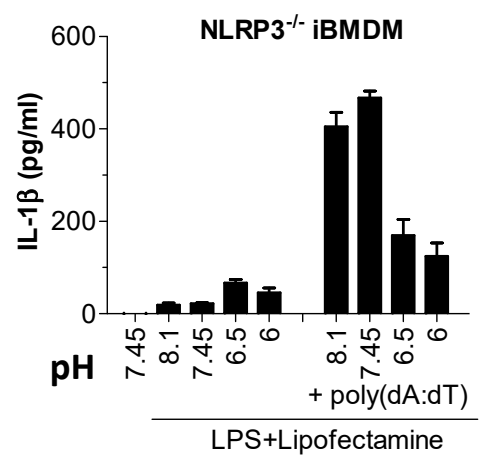

Figure 4. Acidic $\mathrm{pH}$ inhibited NLR family CARD domain-containing 4 (NLRC4) inflammasomes and absent in melanoma 2 (AIM2). (a-d) IL-1 $\beta$ levels by ELISA assay after wild type (WT) iBMDMs $(\mathbf{a}, \mathbf{b})$ or $\mathrm{NLRP}^{-/-}$iBMDMs $(\mathbf{c}, \mathbf{d})$ were primed with $100 \mathrm{ng} / \mathrm{mL}$ LPS for $6 \mathrm{~h}$ and then exposed to buffers with various $\mathrm{pH}$ values alone, containing $3 \mu \mathrm{g} / \mathrm{mL}$ Saty flagellin with DOTAP transfection reagent $(\mathbf{a}, \mathbf{c})$ or $2 \mu \mathrm{g} / \mathrm{mL}$ poly(dA:dT) with Lipofectamine transfection reagent $(\mathbf{b}, \mathbf{d})$ for $3 \mathrm{~h}$.

\section{5. pH Sensitivity Occurred Upstream of ASC Speck Formation}

We next focused on identifying the stage in the inflammasome activation cascade, affected by the acidic conditions. We hypothesized that the cytokine secretory mechanism might be dysfunctional, and thus we measured the upstream event-caspase-1 activation. As already expected, due to the acidosis-related inhibitory effect on the pyroptosis (Figure 2b), caspase-1 cleavage was also inhibited under acidic conditions (Figure 5a). As caspase- 1 activation is upstream of cytokine maturation, the cytokine release is likely not alleviated directly due to the impaired secretory mechanisms. Next, we investigated the relationship between the $\mathrm{pH}$ and the adaptor protein ASC speck formation since it has been reported that in vitro formation of ASC filaments is favored by alkaline $\mathrm{pH}$ conditions whereas lowering the $\mathrm{pH}$ leads to their disassembly [25]. Indeed, visualization of immunofluorescently labelled endogenous ASC specks in fixed iBMDMs after they had been treated with nigericin in 
various $\mathrm{pH}$ buffers revealed that the formation of ASC specks was inhibited when stimulated under acidic conditions (Figure $5 b$ ). ASC protein expression was not affected with the incubation in low $\mathrm{pH}$ buffers alone, as shown by Western blot (Figure 5a). The expression of the sensor protein NLRP3 (Figure 5a) was similarly unaffected by acidosis. To confirm or refute the $\mathrm{pH}$ sensitivity at the level of the ASC speck formation, we activated NLRC4 inflammasome in the ASC-deficient iBMDMs. Namely, for the NLRC4 inflammasome activation, ASC is not obligatory as pro-caspase- 1 can bind the activated NLRC4 sensor protein directly [26]. As the ASC-deficient cells responded in a similarly $\mathrm{pH}$-sensitive fashion to activation under low $\mathrm{pH}$ (Figure 5c), we concluded that low $\mathrm{pH}$-mediated defects in ASC oligomerization might originate from a process upstream of ASC, possibly at the level of the sensor protein.

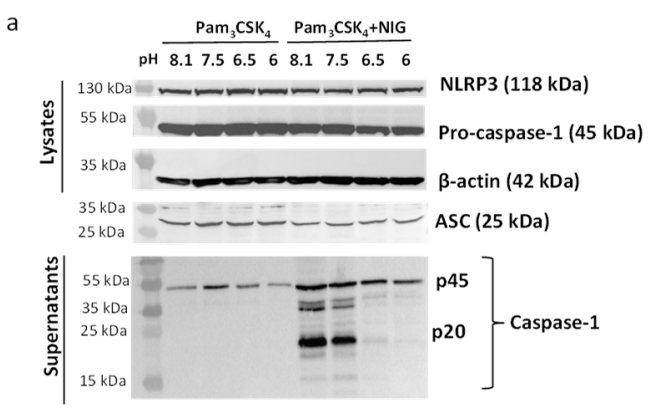

b
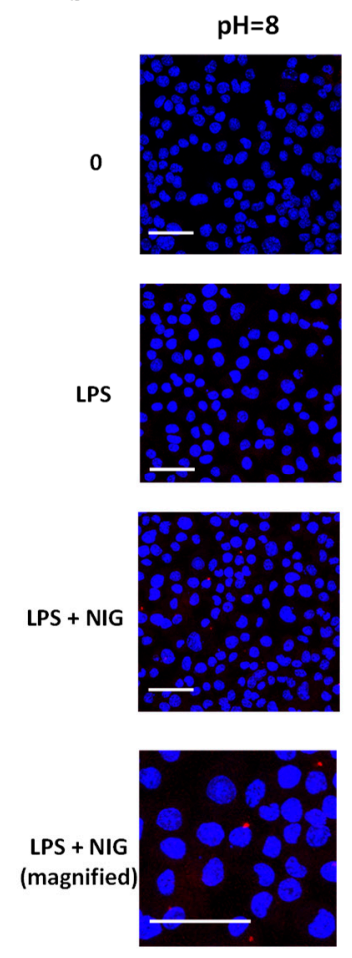
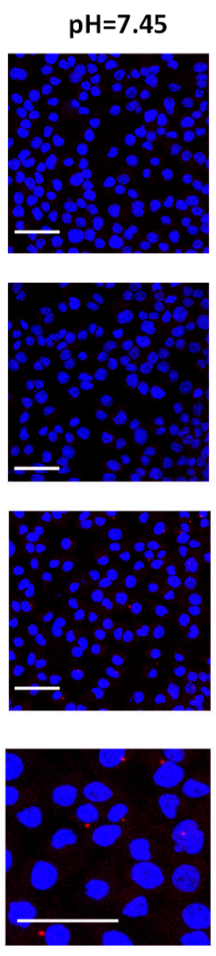

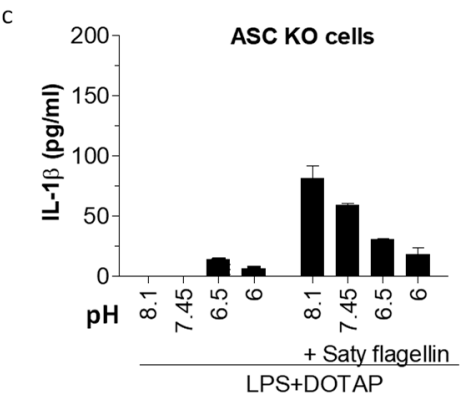

$\mathrm{pH}=6.5$
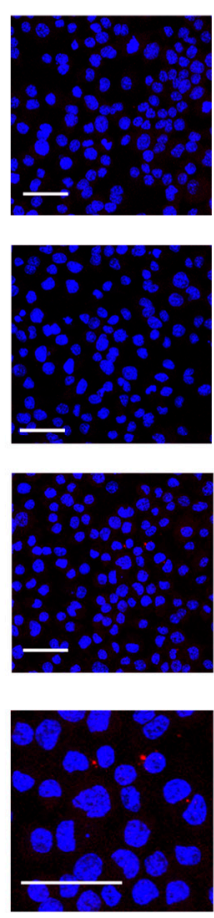
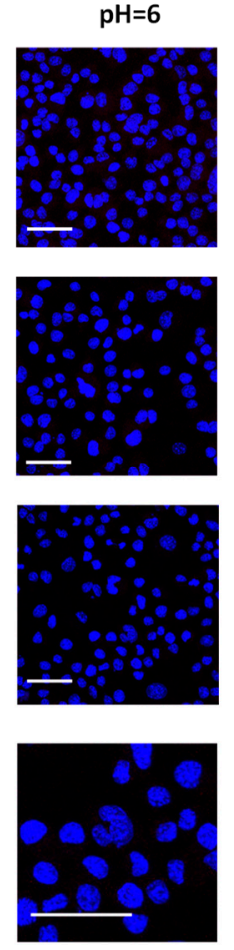

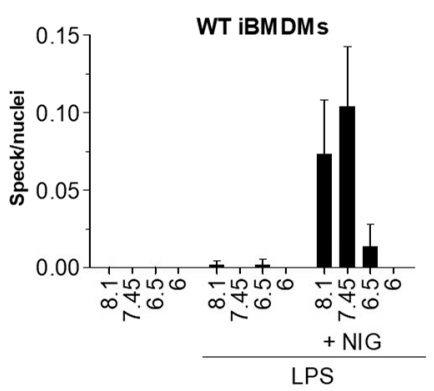

Figure 5. $\mathrm{pH}$ sensitivity was conferred upstream of apoptosis-associated speck-like protein containing a caspase activation and recruitment domain (ASC) oligomerization. (a) Detection of caspase-1 in supernatants and pro-caspase-1, NLRP3, and ASC in lysates with Western blot after iBMDMs were treated overnight with $200 \mu \mathrm{g} / \mathrm{mL}$ Pam3CSK4 and $1 \mathrm{~h}$ with $10 \mu \mathrm{M}$ nigericin or buffers alone. (b) Detection of ASC specks (red aggregates) in immunofluorescently labelled WT iBMDM with confocal microscopy after cells were primed with $100 \mathrm{ng} / \mathrm{mL}$ LPS, followed by caspase-1 inhibition by $30 \mathrm{~min}$ treatment 
with $100 \mu \mathrm{M}$ acYVAD and $1 \mathrm{~h}$ incubation in buffers with various $\mathrm{pH}$ values alone or containing $10 \mu \mathrm{M}$ nigericin. Nuclei were stained with DAPI (blue). Scale $=40 \mu \mathrm{m}$. Images were quantified by determining the number of specks/number of nuclei ratio for $6 \mathrm{z}$-stack image frames for each experimental condition. (c) IL-1 $\beta$ levels by ELISA in supernatants of $\mathrm{ASC}^{-/-}$iBMDMs after overnight priming with $100 \mathrm{ng} / \mathrm{mL}$ LPS and subsequent incubation in buffers with various $\mathrm{pH}$ values alone or containing Saty flagellin in DOTAP transfection reagent.

\section{Discussion}

Extracellular $\mathrm{pH}$ is subject to change in various pathological conditions such as ischemia, hypoxia, atherosclerosis, and tumor microenvironment. The effect of acidosis on the prominent proinflammatory IL-1 $\beta$ cytokine secretion from macrophages is of specific interest as the main IL-1 $\beta$ regulators-inflammasomes-are implicated to play a contributing role in many of these conditions $[27,28]$. Conflicting literature reports on the relationship between the inflammatory responses and $\mathrm{pH}$ change might be due to the considerable species-specific differences in inflammatory response regulated by the innate immunity [9]. In this study, we systematically explored the effects of pathologically relevant acidosis on the IL- $1 \beta$ release in various human- and mouse-derived cell lines.

We observed different IL-1 $\beta$ secretion patterns of human and mouse macrophages in response to changes in extracellular $\mathrm{pH}$. While human macrophages exhibited an increase in IL-1 $\beta$ under mildly acidic $\mathrm{pH}$ that acted additively with NLRP3 triggers, which agrees with the previously reported findings [16,17], mouse macrophages secreted no detectable IL- $1 \beta$ in response to acidosis. Rather, low $\mathrm{pH}$ appeared to act antagonistically with various NLRP3 inflammasome triggers, as we observed markedly decreased IL-1 $\beta$ levels in response to soluble and particulate canonical triggers as well as in the case of CAPS-associated constitutive activation. A growing number of studies report human phagocyte-specific IL-1 $\beta$ secretory patterns that cannot be observed in mouse cells. LPS in human cells can stimulate potassium efflux and pyroptosis-independent IL-1 $\beta$ release in the absence of secondary trigger $[19,29]$. This has recently been reported to occur through a pathway involving Toll-like receptor 4 (TLR4), TIR domain-containing adaptor-inducing interferon- $\beta$ (TRIF), receptor-interacting serine/threonine-protein kinase 1 (RIPK1), Fas-associated protein with death domain (FADD) and caspase-8 [19]. Furthermore, an additional level of NLRP3 inflammasome by alternative splicing was observed in human cells but not in murine cells [30].

We demonstrated that once the physiological $\mathrm{pH}$ conditions were reestablished, the activation of NLRP3 inflammasome was reversible, which indicates that such conditions did not irreversibly inactivate the key protein components of the inflammasome complex. Full reversibility of the process might also be suggestive of a protective negative regulation when cells are exposed to low $\mathrm{pH}$ in order to prevent inflammation-related damage. Acidosis is reported to have a protective role against cell death during ischemia reperfusion, as the fast normalization of $\mathrm{pH}$ paradoxically worsens the injury due to reactive oxygen species (ROS) formation and onset of the mitochondrial permeability transition pore [31]. Direct acidic infusion at the onset of reperfusion in a mouse model was reported to delay the recovery of normal $\mathrm{pH}$ and prevent the myocardium ischemia reperfusion injury [2]. Acidic extracellular conditions either alone (such as lactate) or in combination with NLRP3 activators were previously shown to lead to cathepsin D processing of pro-IL-1 $\beta$ yielding the p20 fragment [32-34]. As this fragment was proposed to be biologically less active [35], decreasing the pool of pro-IL-1 $\beta$ was suggested as a protective strategy. In our case, we observed the p20 fragment even at a neutral $\mathrm{pH}$, suggesting that the major contribution to the decreased secreted levels of IL- $1 \beta$ originates from decreased p17 IL-1 $\beta$.

We showed that human NLRP3, when expressed in the mouse macrophages, did not support IL-1 $\beta$ activation under acidic conditions, but rather reflected the same IL- $1 \beta$ secretion phenotype found with mouse NLRP3. This suggests that differential response of cell species to acidosis is likely not specific to the amino acid sequence of the sensor protein. This fact is further supported by the observation that IL- $1 \beta$ release is also inhibited in response to stimulation of $\mathrm{NLRP}^{-/-}{ }^{- \text {-immortalized }}$ 
bone marrow-derived macrophages with NLRC4 and AIM2 inflammasome activators under acidic conditions, which extends the $\mathrm{pH}$ sensitivity to NLRP3-independent IL- $1 \beta$ sources.

Given the therapeutic implications of IL-1 $\beta$ and pyroptosis inhibition in the context of inflammasome-associated pathologies, we decided to identify the $\mathrm{pH}$-sensitive stage of the inflammasome assembly cascade in mouse macrophages when exposed to extracellular acidosis. We found that caspase- 1 activation and ASC speck formation were both inhibited while procaspase-1 and ASC protein levels were not affected, thus suggesting that an upstream stage of activation governs the $\mathrm{pH}$ sensitivity. The same phenotype was observed for ASC-independent, NLRC4-mediated IL-1 $\beta$ processing, thus suggesting that $\mathrm{pH}$ might affect sensor protein oligomerization. However, as ASC polymerization was $\mathrm{pH}$-sensitive in vitro [25] and depended on ion fluxes in cell culture, where chloride efflux was shown to lead to dynamic inactive ASC aggregates [36], the effect of pH on ASC speck formation cannot simply be excluded.

Our findings of differential inflammasome response to extracellular acidosis in human and mouse macrophages imply that caution is necessary when translating findings of mouse model research to the progression of the inflammatory pathologies in humans. Atherosclerosis mouse models where mice develop milder forms of the disease have already been shown to be of limited value unless transgenic mice are used [8]. This has been attributed to differential NF- $\mathrm{kB}$ pathway sensitivity to low $\mathrm{pH}$ [8]. Similar species-specific discrepancies occur in reports studying the effects of hypoxia, a condition accompanied with acidosis. While the mouse models of several chronic inflammatory conditions such as ulcerative colitis and Crohn's disease provide mounting evidence that hypoxia resolves inflammation [28], studies on human donors or human cell lines conversely often find that hypoxic conditions increase inflammatory responses, e.g., by blocking the hydroxilation of factors within the NF-KB signaling pathway [37]. Similarly, exposure to conditions of low oxygen partial pressure associated with air travel or altitude-related hypoxia increase the risk of flare-ups in patients with irritable bowel syndromes (IBD) and found increased expression of inflammatory cytokines in the intestines of healthy individuals when exposed to high altitude-related hypoxia [38-40]. The results of our study emphasize that species-specific differences in $\mathrm{pH}$ sensitivity of IL- $1 \beta$ release should be considered when drawing conclusions from mouse models of chronic IL-1 $\beta$-related inflammatory conditions.

\section{Materials and Methods}

\subsection{Materials}

The following chemicals and kits were used: cell culture media, fetal bovine serum (FBS), and other cell culture supplies (GIBCO, Thermofischer Scientific, Waltham, MA, USA); DMSO, ultra-pure LPS from Escherichia coli O111:B4, and Imject Alum (Thermofischer Scientific, Waltham, MA, USA); nanoSiO 2 (nanoparticles of silica), naked poly (dA:dT), imiquimod and $\mathrm{Pam}_{3} \mathrm{CSK}_{4}$ (Invivogen, San Diego, CA, USA); nigericin, ATP, doxycycline, and XTT (Sigma, St. Louis, MO, USA); IL-1 beta mouse and human uncoated ELISA Kit (Thermofischer Scientific, Waltham, MA, US); Lipofectamine 2000 (Thermofischer Scientific, Waltham, MA, USA); paraformaldehyde (Electron Microscopy Sciences, Hatfield, PA, USA); SepMate isolation tubes (Stemcell Technologies, Vancouver, BC, Canada); Prolong Diamond Antifade solution with DAPI (Invitrogen, Thermofischer Scientific, Waltham, MA, USA); DOTAP Liposomal Transfection Reagent (Roche, Basel, Switzerland); Retro-X Tet-On 3G inducible expression system (Takara, Clontech, Kusatsu, Shiga Prefecture, Japan), LDH Cytotoxicity Assay (Roche, Basel, Switzerland). The following antibodies were used: purified anti-ASC antibodies (TMS-1, clone HASC-71) (Biolegend, San Diego, CA, USA), Alexa Fluor 633 goat anti-mouse IgG (H+L) (Invitrogen, Thermofischer Scientific, Waltham, MA, USA), anti-caspase-1 (p20) (mouse) Casper-1 (Adipogen, Liestal, Switzerland), HRP-conjugated goat anti-mouse IgG $(\mathrm{H}+\mathrm{L})$ polyclonals (Jackson ImmunoResearch, West Grove, PA, USA), rabbit polyclonal anti-mouse IL-1beta (GeneTEX, Irvine, CA, USA), goat polyclonal to rabbit IgG (HRP) (Abcam, Cambridge, UK), $\beta$-actin (8H10D10) 
anti-mouse mAb (Cell Signaling Technology, Danvers, MA, USA), and anti-NLRP3/NALP3 mAb Cryo-2 (Adipogen, Liestal, Switzerland).

\subsection{Cell Cultures}

Immortalized bone marrow-derived macrophages (iBMDMs) [41] and immortalized microglia [42] from C57BL/6 mice were a kind gift from Kate A. Fitzgerald and Douglas Golenbock (University of Massachusetts Medical School, Worcester, MA, USA), while BLaER1 [19,43] were a kind gift from Thomas Graf (Centre for Genomic Regulation, Barcelona, Spain). NLRP3 ${ }^{\mathrm{R} 260 \mathrm{~W}}$, human and mouse full length NLRP3, human NLRP3 $3^{1-688}$, and mouse NLRP3 ${ }^{1-686}$ (all previously reported by us $[23,44]$ ) were constructed on the NLRP3 ${ }^{-/-}$iBMDM background using a Retro-X Tet-On 3G inducible expression system (Takara, Clontech) as previously described [23]. THP-1 (from The European Collection of Authenticated Cell Cultures, ECACC, Wiltshire, UK), PBMCs, and primary mouse bone marrow-derived macrophages (BMDM) were cultured and seeded in RPMI medium supplemented with 10\% FBS, while RPMI with 25 mM HEPES, 2\% PenStrep, 1\% L-glutamate (200 mM), 0.1\% 2 - $\beta$-mercaptoethanol $(50 \mathrm{mM})$, and $10 \%$ FBS was used for BLaER1 cells. DMEM medium supplemented with 10\% FBS was used for other cell lines. As previously reported, BLaER1 were transdifferentiated into monocytes using $100 \mathrm{nM} \beta$-estradiol E2 (Calbiochem, San Diego, CA, USA), $10 \mathrm{ng} / \mathrm{mL}$ hrIL-3 (PeproTech, Rocky Hill, NJ, USA), and 10 ng/mL hr-CSF-1 (M-CSF) for 5 days, while THP-1 were differentiated by an overnight incubation with $100 \mathrm{ng} / \mathrm{mL}$ phorbol 12-myristate 13-acetate (PMA) [19]. With the exception of priming (and differentiation) of PBMC, THP-1, BLaER1, and primary mouse BMDM that was performed in RPMI supplemented with 10\% FBS, we performed all experiments in serum-free DMEM and stimulation buffer.

\subsection{Isolation of PBMC and Primary Mouse BMDM}

PBMC were isolated from blood of healthy volunteers using SepMate isolation tubes according to the manufacturer's instructions (Stemcell Technologies, Vancouver, BC, Canada) after obtaining an appropriate permit from the National Ethical Committee (0120-21/2020/4). Primary mouse BMDMs were isolated from femur and tibia bones of sacrificed mouse for which we obtained the postmortem tissue collection permit from the Administration for Food Safety, Veterinary Sector and Plant Protection (U34401-3/2018/4). Bone marrow was washed out of the bones with a PBS-loaded syringe and was centrifuged for $5 \mathrm{~min}$ at $1200 \mathrm{rpm}$. Erythrocytes were lysed by incubation in $\mathrm{NH}_{4} \mathrm{Cl}$ buffer for $15 \mathrm{~min}$ at $37^{\circ} \mathrm{C}$, followed by centrifugation and aspiration of the supernatant. The pellet was washed in PBS, and after centrifugation was resuspended in DMEM $+20 \%$ FBS. We plated $1 \times 10^{7}$ cells per Petri dish and grew them in the presence of MCSF differentiation factor and PenStrep for 6 days. Cells were subsequently frozen.

\subsection{Inflammasome Stimulation}

Cells were seeded in DMEM with $10 \%$ FBS at $1.6 \times 10^{5}$ per well for the 96 -well plate (ELISA, LDH, and XTT assays), at $1.6 \times 10^{6}$ per well for the 6-well plate (Western blotting), and at $2.8 \times 10^{5}$ cells per well for 8-well lides (immunofluorescence). The next day, cells were primed for $6 \mathrm{~h}$ with $100 \mathrm{ng} / \mathrm{mL}$ ultra-pure lipopolysaccharide (LPS) or overnight with $200 \mathrm{ng} / \mathrm{mL} \mathrm{Pam}_{3} \mathrm{CSK}_{4}$. After medium removal, cells were stimulated with instigators in stimulation buffer of various $\mathrm{pH}$ values $(8.1,7.45$, 6.5 and 6). Stimulation buffer was composed of $10 \mathrm{mM}$ HEPES, $147 \mathrm{mM} \mathrm{NaCl}, 2 \mathrm{mM} \mathrm{KCl}, 13 \mathrm{mM}$ D-glucose, $2 \mathrm{mM} \mathrm{CaCl}{ }_{2} \times 2 \mathrm{H}_{2} \mathrm{O}$, and $1 \mathrm{mM} \mathrm{MgCl}{ }_{2} \times 6 \mathrm{H}_{2} \mathrm{O}$, and was previously reported for use in inflammasome activation [45]. For $\mathrm{K}^{+}$efflux inhibition, stimulation buffers were made with $134 \mathrm{mM}$ $\mathrm{KCl}$. Inflammasome instigators in stimulation buffer were added to the cells for $1 \mathrm{~h}(10 \mu \mathrm{M}$ nigericin, $5 \mathrm{mM}$ ATP) or $3 \mathrm{~h}\left(1 \mu \mathrm{g} / \mathrm{mL}\right.$ poly (dA:dT)/Lipofectamine, $400 \mu \mathrm{g} / \mathrm{mL}$ alum, $180 \mu \mathrm{g} / \mathrm{mL}$ nanoSiO ${ }_{2}$, $3 \mu \mathrm{g} / \mathrm{mL}$ wild type (WT) Saty flagellin/DOTAP, $20 \mu \mathrm{M}$ imiquimod, $1 \mathrm{mM}$ LLOMe). DOTAP and lipofectamine were used according to the manufacturer's instructions. Saty flagellin was produced and used for stimulation as previously described [46]. As controls, we used DOTAP and lipofectamine 
without instigators. For experiments involving doxycycline-induced NLRP3 expression in the Retro-X Tet-On 3G inducible expression system (Takara, Kusatsu, Shiga Prefecture, Japan), we seeded cells in DMEM with $10 \%$ FBS at $1.2 \times 10^{5}$ cells per well of a 96-well plate that was left overnight. Afterwards, NLRP3 expression and inflammasome priming were stimulated with a combination of $200 \mathrm{ng} / \mathrm{mL}$ $\mathrm{Pam}_{3} \mathrm{CSK}_{4}$ and $0.5 \mu \mathrm{g} / \mathrm{mL}$ doxycycline (DOX) for $9 \mathrm{~h}$. Then, cells were stimulated for $1 \mathrm{~h}$ in buffers of various $\mathrm{pH}$ values alone or in the presence of $10 \mu \mathrm{M}$ nigericin. Supernatants were collected and analyzed for IL-1 $\beta$ in ELISA assay.

\subsection{Cytokine Detection Using ELISA Assays}

IL-1 $\beta$ was detected in cell supernatants using mouse and human IL-1 beta uncoated ELISA Kit according to the manufacturer's instructions (Thermofisher Scientific, Waltham, MA, USA). Multiplate reader SinergyMx (BioTek, Winooski, VT, USA) was used to measure absorbance.

\subsection{Protein Detection Using Western Blotting}

Cell stimulation was performed in a 6-well plate format. For caspase-1 and IL-1 $\beta$ detection, we concentrated the supernatant using $3 \mathrm{~K}$ Amicon Ultra- $0.5 \mathrm{~mL}$ centrifugal filters (Merck) and performed centrifugation at $14,000 \times g$ at $4{ }^{\circ} \mathrm{C}$. Concentrate was mixed with SDS and $\beta$-mercaptoethanol loading buffer and was denatured at $90^{\circ} \mathrm{C}$ for $10 \mathrm{~min}$. For pro-caspase- 1 and pro-IL-1 $\beta$ detection, we washed cells twice with cold PBS and lysed them. Protein concentration in the cell lysate was measured with BCA and mixed with SDS and $\beta$-mercaptoethanol loading buffer. A total of $30 \mu \mathrm{g}$ proteins per well were separated on $12 \%$ or $15 \%$ SDS-PAGE gels, blotted onto the nitrocellulose membrane (GE Healthcare, Chicago, IL, USA), and detected using iBIND Automated Western System (Thermofisher Scientific, Waltham, MA, USA) with appropriate primary and secondary antibodies. For caspase-1 and pro-caspase-1 detection, we used the anti-caspase-1 p20 antibody Casper-1 (1:1000, Adipogen, San Diego, CA, USA), followed by HRP-conjugated goat anti-mouse IgG $(\mathrm{H}+\mathrm{L})$ polyclonal antibodies (1:600, Jackson ImmunoResearch, West Grove, PA, USA). IL-1 $\beta$ and pro-IL-1 $\beta$ were detected using rabbit polyclonal anti-mouse IL-1beta (1:1000, GeneTEX, Irvine, CA, USA) as a primary antibody and goat polyclonal to rabbit IgG (HRP) (1:600, Abcam, Cambridge, UK) as a secondary antibody. As a loading control reference in the case of lysates, we used either $\beta$-actin (8H10D10) mouse mAb (1:1000, Cell Signaling technology, Danvers, MA, USA) followed by HRP-conjugated goat anti-mouse IgG (H+L) polyclonals (1:600, Jackson ImmunoResearch, West Grove, PA, USA) or nonspecific band. SuperSignal West Femto or Pico Chemiluminescent Substrate (Thermo Scientific, Waltham, MA, USA) were used for detection of HRP-labeled bands.

\subsection{Viability Evaluation Using XTT and LDH Assay}

Freshly collected cell supernatants following stimulation were used for the end-point lactate dehydrogenase (LDH) activity measurement assay according to the manufacturer's instructions (LDH Cytotoxicity Assay, Roche, Basel, Switzerland). On the cells, we performed XTT test to determine their viability/metabolic activity. For XTT assay, we used DMEM without phenol red and added to it a solution of tetrazolium salt (XTT) and phenazine methosulphate (PMS). Upon colour development we measured absorbance at $490 \mathrm{~nm}$ using a multiplate reader SinergyMx (BioTek, Winooski, VT, USA).

\subsection{Confocal Microscopy}

Immunofluorescent labeling of endogenous ASC was performed in fixed and permeabilized WT iBMDMs, as previously described [45,47]. ASC specks were detected using purified anti-ASC (TMS-1, clone HASC-71) primary antibodies (1:500, Biolegend, San Diego, CA, USA) and Alexa Fluor 633 goat anti-mouse IgG (H+L) (1:200, Invitrogen, Thermo Scientific, Waltham, MA, USA) as secondary antibodies. A Leica TCS SP5 laser scanning microscope mounted on a Leica DMI 6000 CS inverted microscope (Leica Microsystems, Wetzlar, Germany) with the HCX plan apo 63× (numerical aperture 1.4) oil immersion objective was used for imaging. A $405 \mathrm{~nm}$ laser line of $20 \mathrm{~mW}$ diode laser was used 
for DAPI excitation with emission between 415 and $450 \mathrm{~nm}$. A $1 \mathrm{~mW}$ 631-nm HeNe laser was used for Alexa Fluor 633 anti-ASC excitation with emitted light detected between 640-660 nm. LAS AF (Leica, Wetzlar, Germany) and ImageJ software were used to acquire and process images.

\subsection{Intracellular $\mathrm{pH}$ Estimation}

In order to determine the change in cytosolic $\mathrm{pH}$, we established a mouse macrophage cell line constitutively expressing a ratiometric green fluorescent protein (GFP) variant pHluorin that we previously optimized in our group [20,21], with dual excitation at $405 \mathrm{~nm}$ (deprotonated form) and $488 \mathrm{~nm}$ (protonated form). Cells were primed and stimulated with various triggers, upon which we measured the pHluorin fluorescence by ratiometric flow cytometry on the CyFlow Space cytometer (Partec, Germany). As described previously [48], we used split optics for 405- and 488-nm light path line. For excitation of protonated form, we used a blue solid-state laser that emits $50 \mathrm{~mW}$ of light at $488 \mathrm{~nm}$ and collected fluorescence using a standard 536/40-nm bandwidth band-pass filter (F488-nm channel). For excitation of the deprotonated form, we used a violet diode laser that emits $100 \mathrm{~mW}$ of light at $405 \mathrm{~nm}$ and detected fluorescence using a 480-nm dichroic mirror, with a 520/20-nm bandwidth band-pass filter (F405-nm channel) being used. A side-scatter signal was used as the trigger signal. We then gated the cells and analyzed at least 20,000 cells at the rate 200 cells/s.

Supplementary Materials: Supplementary materials can be found at http://www.mdpi.com/1422-0067/21/19/ 7229/s1.

Author Contributions: Methodology, investigation, and writing, P.S.; methodology, M.B.; conceptualization and writing, I.H.-B. All authors have read and agreed to the published version of the manuscript.

Funding: This research was funded by the Slovenian Research Agency, project grant J3-1746 to I.H.B., and core funding P4-176 and Young Researcher grant to P.S. I.H.-B. is a recipient of the ICGEB grant (CRPSVN18-01).

Acknowledgments: We would like to thank Duško Lainšček for help with primary cell isolation. We are thankful to Kate A. Fitzgerald and Douglas Golenbock (University of Massachusetts Medical School, Worcester, MA, USA) who provided us with the immortalized bone marrow-derived macrophages and immortalized microglial cells, as well as to Thomas Graf (Centre for Genomic Regulation, Barcelona, Spain) for providing us with BLaER1 cells. We are thankful to Elvira Boršič, Robert Bremšak, Darija Oven, Irena Škraba, and Sanjin Lulić for technical assistance.

Conflicts of Interest: The authors declare no conflict of interest.

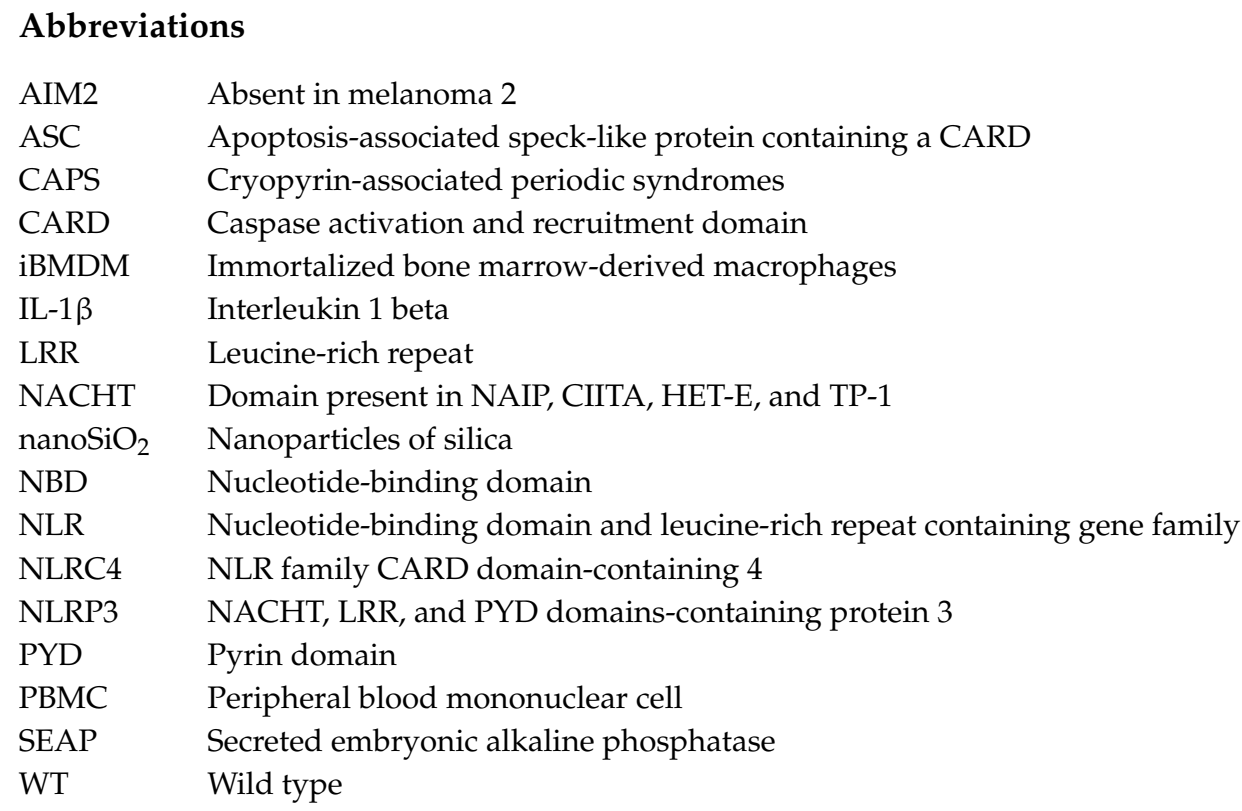




\section{References}

1. Ö̈örni, K.; Rajamäki, K.; Nguyen, S.D.; Lähdesmäki, K.; Plihtari, R.; Lee-Rueckert, M.; Kovanen, P.T. Acidifi cation of the intimal $\mathrm{fl}$ uid: The perfect storm for atherogenesis. J. Lipid Res. 2015, 56, 203-214. [CrossRef] [PubMed]

2. Qiao, X.; Xu, J.; Yang, Q.-J.; Du, Y.; Lei, S.; Liu, Z.-H.; Liu, X.; Liu, H. Transient acidosis during early reperfusion attenuates myocardium ischemia reperfusion injury via PI3k-Akt-eNOS signaling pathway. Oxid. Med. Cell. Longev. 2013, 2013, 126083. [CrossRef] [PubMed]

3. Naghavi, M.; John, R.; Naguib, S.; Siadaty, M.S.; Grasu, R.; Kurian, K.C.; Van Winkle, W.B.; Soller, B.; Litovsky, S.; Madjid, M.; et al. pH heterogeneity of human and rabbit atherosclerotic plaques; a new insight into detection of vulnerable plaque. Atherosclerosis 2002, 164, 27-35. [CrossRef]

4. Cummings, N.A.; Nordby, G.L. Measurement of synovial fluid pH in normal and arthritic knees. Arthritis Rheum. 1966, 9, 47-56. [CrossRef] [PubMed]

5. Corbet, C.; Feron, O. Tumour acidosis: From the passenger to the driver's seat. Nat. Rev. Cancer 2017, 17, 577-593. [CrossRef]

6. Zhang, J.; Koh, J.; Lu, J.; Thiel, S.; Leong, B.S.H.; Sethi, S.; He, C.Y.X.; Ho, B.; Ding, J.L. Local inflammation induces complement crosstalk which amplifies the antimicrobial response. PLoS Pathog. 2009, 5, e1000282. [CrossRef]

7. Huang, C.J.; Haque, I.U.; Slovin, P.N.; Nielsen, R.B.; Fang, X.; Skimming, J.W. Environmental pH regulates LPS-induced nitric oxide formation in murine macrophages. Nitric Oxide Biol. Chem. 2002, 6, 73-78. [CrossRef]

8. Gerry, A.B.; Leake, D.S. Effect of low extracellular $\mathrm{pH}$ on NF-kB activation in macrophages. Atherosclerosis 2014, 233, 537-544. [CrossRef]

9. Schroder, K.; Irvine, K.M.; Taylor, M.S.; Bokil, N.J.; Le Cao, K.A.; Masterman, K.A.; Labzin, L.I.; Semple, C.A.; Kapetanovic, R.; Fairbairn, L.; et al. Conservation and divergence in Toll-like receptor 4-regulated gene expression in primary human versus mouse macrophages. Proc. Natl. Acad. Sci. USA 2012, 109, E944-E953. [CrossRef]

10. Muñoz-Planillo, R.; Kuffa, P.; Martínez-Colón, G.; Smith, B.; Rajendiran, T.; Núñez, G. K+ Efflux Is the Common Trigger of NLRP3 Inflammasome Activation by Bacterial Toxins and Particulate Matter. Immunity 2013, 38. [CrossRef]

11. Tang, T.; Lang, X.; Xu, C.; Wang, X.; Gong, T.; Yang, Y.; Cui, J.; Bai, L.; Wang, J.; Jiang, W.; et al. CLICs-dependent chloride efflux is an essential and proximal upstream event for NLRP3 inflammasome activation. Nat. Commun. 2017, 8, 202. [CrossRef] [PubMed]

12. Hafner-Bratkovič, I.; Pelegrín, P. Ion homeostasis and ion channels in NLRP3 inflammasome activation and regulation. Curr. Opin. Immunol. 2018, 52, 8-17. [CrossRef]

13. Rathinam, V.A.; Vanaja, S.K.; Fitzgerald, K.A. Regulation of inflammasome signaling. Nat. Immunol. 2012, 13, 332-333. [CrossRef] [PubMed]

14. Gross, O.; Thomas, C.J.; Guarda, G.; Tschopp, J. The inflammasome: An integrated view-Order.aspx. Immunol. Rev. 2011, 243, 136-151. [CrossRef] [PubMed]

15. Evavold, C.L.; Kagan, J.C. Inflammasomes: Threat-Assessment Organelles of the Innate Immune System. Immunity 2019, 51, 609-624. [CrossRef]

16. Jancic, C.C.; Cabrini, M.; Gabelloni, M.L.; Rodríguez Rodrigues, C.; Salamone, G.; Trevani, A.S.; Geffner, J. Low extracellular $\mathrm{pH}$ stimulates the production of IL-1 $\beta$ by human monocytes. Cytokine 2012, 57, 258-268. [CrossRef]

17. Rajamäki, K.; Nordström, T.; Nurmi, K.; Åkerman, K.E.O.; Kovanen, P.T.; Öörni, K.; Eklund, K.K. Extracellular acidosis is a novel danger signal alerting innate immunity via the NLRP3 inflammasome. J. Biol. Chem. 2013, 288, 13410-13419. [CrossRef]

18. Riemann, A.; Wußling, H.; Loppnow, H.; Fu, H.; Reime, S.; Thews, O. Acidosis differently modulates the inflammatory program in monocytes and macrophages. Biochim. Biophys. Acta Mol. Basis Dis. 2016, 1862, 72-81. [CrossRef]

19. Gaidt, M.M.; Ebert, T.S.; Chauhan, D.; Schmidt, T.; Schmid-Burgk, J.L.; Rapino, F.; Robertson, A.A.B.; Cooper, M.A.; Graf, T.; Hornung, V. Human Monocytes Engage an Alternative Inflammasome Pathway. Immunity 2016, 44. [CrossRef] 
20. Miesenböck, G.; De Angelis, D.A.; Rothman, J.E. Visualizing secretion and synaptic transmission with pH-sensitive green fluorescent proteins. Nature 1998, 394, 192-195. [CrossRef]

21. Bagar, T.; Altenbach, K.; Read, N.D.; Bencina, M. Live-Cell imaging and measurement of intracellular $\mathrm{pH}$ in filamentous fungi using a genetically encoded ratiometric probe. Eukaryot. Cell 2009, 8, 703-712. [CrossRef] [PubMed]

22. Lagadic-Gossmann, D.; Huc, L.; Lecureur, V. Alterations of intracellular pH homeostasis in apoptosis: Origins and roles. Cell Death Differ. 2004, 11, 953-961. [CrossRef] [PubMed]

23. Hafner-Bratkovič, I.; Sušjan, P.; Lainšček, D.; Tapia-Abellán, A.; Cerović, K.; Kadunc, L.; Angosto-Bazarra, D.; Pelegrin, P.; Jerala, R. NLRP3 lacking the leucine-rich repeat domain can be fully activated via the canonical inflammasome pathway. Nat. Commun. 2018, 9, 5182. [CrossRef] [PubMed]

24. Man, S.M.; Hopkins, L.J.; Nugent, E.; Cox, S.; Gluck, I.M.; Tourlomousis, P.; Wright, J.A.; Cicuta, P.; Monie, T.P.; Bryant, C.E. Inflammasome activation causes dual recruitment of NLRC4 and NLRP3 to the same macromolecular complex. Proc. Natl. Acad. Sci. USA 2014, 111, 7403-7408. [CrossRef] [PubMed]

25. Nambayan, R.J.T.; Sandin, S.I.; Quint, D.A.; Satyadi, D.M.; de Alba, E. The inflammasome adapter ASC assembles into filaments with integral participation of its two Death Domains, PYD and CARD. J. Biol. Chem. 2019, 294, 439-452. [CrossRef]

26. Broz, P.; von Moltke, J.; Jones, J.W.; Vance, R.E.; Monack, D.M. Differential requirement for Caspase-1 autoproteolysis in pathogen-induced cell death and cytokine processing. Cell Host Microbe 2010, 8, 471-483. [CrossRef]

27. De Nardo, D.; Labzin, L.I.; Kono, H.; Seki, R.; Schmidt, S.V.; Beyer, M.; Xu, D.; Zimmer, S.; Lahrmann, C.; Schildberg, F.A.; et al. High-density lipoprotein mediates anti-inflammatory reprogramming of macrophages via the transcriptional regulator ATF3. Nat. Immunol. 2014, 15, 152-160. [CrossRef]

28. Cosin-Roger, J.; Simmen, S.; Melhem, H.; Atrott, K.; Frey-Wagner, I.; Hausmann, M.; De Vallière, C.; Spalinger, M.R.; Spielmann, P.; Wenger, R.H.; et al. Hypoxia ameliorates intestinal inflammation through NLRP3/mTOR downregulation and autophagy activation. Nat. Commun. 2017, 8, 1-13. [CrossRef]

29. Netea, M.G.; Nold-Petry, C.A.; Nold, M.F.; Joosten, L.A.B.; Opitz, B.; Van Der Meer, J.H.M.; Van De Veerdonk, F.L.; Ferwerda, G.; Heinhuis, B.; Devesa, I.; et al. Differential requirement for the activation of the inflammasome for processing and release of IL-1 $\beta$ in monocytes and macrophages. Blood 2009, 113, 2324-2335. [CrossRef]

30. Hoss, F.; Mueller, J.L.; Rojas Ringeling, F.; Rodriguez-Alcazar, J.F.; Brinkschulte, R.; Seifert, G.; Stahl, R.; Broderick, L.; Putnam, C.D.; Kolodner, R.D.; et al. Alternative splicing regulates stochastic NLRP3 activity. Nat. Commun. 2019, 10. [CrossRef]

31. Cohen, M.V.; Yang, X.M.; Downey, J.M. Acidosis, oxygen, and interference with mitochondrial permeability transition pore formation in the early minutes of reperfusion are critical to postconditioning's success. Basic Res. Cardiol. 2008, 103, 464-471. [CrossRef] [PubMed]

32. Pelegrin, P.; Surprenant, A. Pannexin-1 couples to maitotoxin- and nigericin-induced interleukin- $1 \beta$ release through a dye uptake-independent pathway. J. Biol. Chem. 2007, 282, 2386-2394. [CrossRef] [PubMed]

33. Takenouchi, T.; Iwamaru, Y.; Sugama, S.; Tsukimoto, M.; Fujita, M.; Sekigawa, A.; Sekiyama, K.; Sato, M.; Kojima, S.; Conti, B.; et al. The activation of P2X7 receptor induces cathepsin D-dependent production of a 20-kDa form of IL-1 $\beta$ under acidic extracellular pH in LPS-primed microglial cells. J. Neurochem. 2011, 117, no. [CrossRef]

34. Edye, M.E.; Lopez-Castejon, G.; Allan, S.M.; Brough, D. Acidosis drives damage-associated molecular pattern (DAMP)-induced interleukin-1 secretion via a caspase-1-independent pathway. J. Biol. Chem. 2013, 288, 30485-30494. [CrossRef] [PubMed]

35. Hazuda, D.J.; Strickler, J.; Kueppers, F.; Simon, P.L.; Young, P.R. Processing of precursor Interleukin 1 beta and inflammatory disease. J. Biol. Chem. 1990, 265, 6318-6322. [PubMed]

36. Green, J.P.; Yu, S.; Martín-Sánchez, F.; Pelegrin, P.; Lopez-Castejon, G.; Lawrence, C.B.; Brough, D. Chloride regulates dynamic NLRP3-dependent ASC oligomerization and inflammasome priming. Proc. Natl. Acad. Sci. USA 2018, 115, E9371-E9380. [CrossRef]

37. Cummins, E.P.; Berra, E.; Comerford, K.M.; Ginouves, A.; Fitzgerald, K.T.; Seeballuck, F.; Godson, C.; Nielsen, J.E.; Moynagh, P.; Pouyssegur, J.; et al. Prolyl hydroxylase-1 negatively regulates IкB kinase- $\beta$, giving insight into hypoxia-induced NFKB activity. Proc. Natl. Acad. Sci. USA 2006, 103, 18154-18159. [CrossRef] 
38. Vavricka, S.R.; Rogler, G.; Maetzler, S.; Misselwitz, B.; Safroneeva, E.; Frei, P.; Manser, C.N.; Biedermann, L.; Fried, M.; Higgins, P.; et al. High altitude journeys and flights are associated with an increased risk of flares in inflammatory bowel disease patients. J. Crohn Colitis 2014, 8, 191-199. [CrossRef]

39. Vavricka, S.R.; Rogler, G.; Biedermann, L. High Altitude Journeys, Flights and Hypoxia: Any Role for Disease Flares in IBD Patients? Proc. Dig. Dis. 2016, 34, 78-83. [CrossRef]

40. Wojtal, K.A.; Cee, A.; Lang, S.; Götze, O.; Frühauf, H.; Geier, A.; Pastor-Anglada, M.; Torres-Torronteras, J.; Martí, R.; Fried, M.; et al. Downregulation of duodenal SLC transporters and activation of proinflammatory signaling constitute the early response to high altitude in humans. Am. J. Physiol. Liver Physiol. 2014, 307, G673-G688. [CrossRef]

41. Hornung, V.; Bauernfeind, F.; Halle, A.; Samstad, E.O.; Kono, H.; Rock, K.L.; Fitzgerald, K.A.; Latz, E. Silica crystals and aluminum salts activate the NALP3 inflammasome through phagosomal destabilization. Nat. Immunol. 2008, 9, 847-856. [CrossRef]

42. Halle, A.; Hornung, V.; Petzold, G.C.; Stewart, C.R.; Monks, B.G.; Reinheckel, T.; Fitzgerald, K.A.; Latz, E.; Moore, K.J.; Golenbock, D.T. The NALP3 inflammasome is involved in the innate immune response to amyloid-beta. Nat. Immunol. 2008, 9, 857-865. [CrossRef]

43. Rapino, F.; Robles, E.F.; Richter-Larrea, J.A.; Kallin, E.M.; Martinez-Climent, J.A.; Graf, T. C/EBP $\alpha$ Induces Highly Efficient Macrophage Transdifferentiation of B Lymphoma and Leukemia Cell Lines and Impairs Their Tumorigenicity. Cell Rep. 2013, 3, 1153-1163. [CrossRef]

44. Sušjan, P.; Roškar, S.; Hafner-Bratkovič, I. The mechanism of NLRP3 inflammasome initiation: Trimerization but not dimerization of the NLRP3 pyrin domain induces robust activation of IL-1ß. Biochem. Biophys. Res. Commun. 2017, 483, 823-828. [CrossRef]

45. Baroja-Mazo, A.; Martín-Sánchez, F.; Gomez, A.I.; Martínez, C.M.; Amores-Iniesta, J.; Compan, V.; Barberà-Cremades, M.; Yagüe, J.; Ruiz-Ortiz, E.; Antón, J.; et al. The NLRP3 inflammasome is released as a particulate danger signal that amplifies the inflammatory response. Nat. Immunol. 2014, 15, 738-748. [CrossRef]

46. Forstnerič, V.; Ivičak-Kocjan, K.; Plaper, T.; Jerala, R.; Benčina, M. The role of the C-terminal D0 domain of flagellin in activation of Toll like receptor 5. PLoS Pathog. 2017, 13, e1006574. [CrossRef]

47. Sušjan, P.; Lainšček, D.; Strmšek, Ž.; Hodnik, V.; Anderluh, G.; Hafner-Bratkovič, I. Selective inhibition of NLRP3 inflammasome by designed peptide originating from ASC. FASEB J. 2020, 34, 11068-11086. [CrossRef]

48. Valkonen, M.; Mojzita, D.; Penttilä, M.; Benčinaa, M. Noninvasive high-throughput single-cell analysis of the intracellular $\mathrm{pH}$ of Saccharomyces cerevisiae by ratiometric flow cytometry. Appl. Environ. Microbiol. 2013, 79, 7179-7187. [CrossRef]

(C) 2020 by the authors. Licensee MDPI, Basel, Switzerland. This article is an open access article distributed under the terms and conditions of the Creative Commons Attribution (CC BY) license (http://creativecommons.org/licenses/by/4.0/). 